\title{
Oxidation Behavior of the Nickel-Based Superalloy DZ125 at $980{ }^{\circ} \mathrm{C}$
}

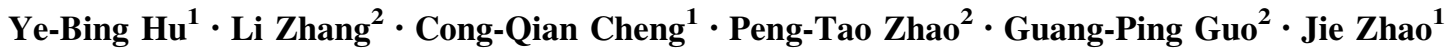

Received: 19 December 2016/Revised: 5 May 2017/Published online: 26 May 2017

(C) The Chinese Society for Metals and Springer-Verlag Berlin Heidelberg 2017

\begin{abstract}
The isothermal oxidation behavior of the nickel-based superalloy DZ125 was investigated at $980{ }^{\circ} \mathrm{C}$ through SEM/EDX and XRD. The weight loss process exhibited three periods-initial, transient and steady stages, which correspond to the formation of three layers on the surface. The outer layer was composed of $\mathrm{NiO}$, whereas the intermediate layer mainly consisted of spinels and was accompanied with Ta-rich oxide. Alumina was evident as the inner continuous layer close to the substrate. The first formation of alumina was responsible for the initial stage of weight loss, and the formation of $\mathrm{NiO}$ and intermediate layer may dramatically affect on the transient and steady stage, respectively. The oxide scales effect on growth mechanism was discussed.
\end{abstract}

KEY WORDS: Nickel-based; Superalloy; Oxidation; Alumina

\section{Introduction}

Nickel-based superalloys are widely used in turbine blade due to their superior high-temperature mechanical properties and oxidation resistance [1]. However, the service environment for turbine blade components is abominable and the work temperature can reach up to $1100{ }^{\circ} \mathrm{C}$. This brings about the high-temperature oxidation, which is the main factor to limit the service life of the superalloy [2]. When the superalloy operates at oxidation circumstance, on the one hand, the oxide morphology on the surface and the oxide growth process can destroy the microstructure integrality, especially change the strengthening phase

Available online at http://link.springer.com/journal/40195.

Jie Zhao

jiezhao@dlut.edu.cn

1 School of Materials Science and Engineering, Dalian University of Technology, Dalian 116024, China

2 Beijing Institute of Aeronautical Materials, Beijing 100095, China morphology [3]. Then, it causes a mechanical properties gradient from the surface to the bulk materials which has a very weak creep resistance [4-7]; on the other hand, the oxides itself are inherently brittle materials inducing crack initiation and therefore reducing turbine component creep life [8-11]. Therefore, high-temperature oxidation mechanism of nickel-based superalloys plays an important role in optimizing the design and durability analysis of turbine blade.

Up to now although much effort has been conducted on the oxidation kinetics and study of the oxide film of superalloy, the oxidation mechanism has not been thoroughly understand. It has been generally accepted [12-14] that the oxidation weight changes of superalloys follow parabolic or sub-parabolic law during whole oxidation process, but some researchers reported different kinetics differences at various oxidation periods. For example, Dryepondt and Monceau [15] found the transient stage and steady stage in the oxidation kinetic curve of MC2 single crystal superalloy during isothermal oxidation at $1150{ }^{\circ} \mathrm{C}$. Yuan et al. [16] reported that there are three distinct stages on the mass gain curves of a $\mathrm{Fe}-\mathrm{Mn}-\mathrm{Al}-\mathrm{C}$ austenitic steel when the temperature was higher than $800{ }^{\circ} \mathrm{C}$. Pfennig and 
Fedelich [14] found that two distinguished oxidation stages are observed when they studied the oxidation behavior of single crystal PWA1483. Pei et al. [17] reported that the oxidation behavior of DD6 can be roughly divided into three stages resulting from the spalling of the oxide film as the exposure time increased. Although the oxidation kinetics of the superalloy has been widely studied, only few studies on the mechanism of kinetics and no pay attention to the relationship between the oxide growth and the oxidation kinetics at the different exposure time.

DZ125 nickel-based superalloy produced in China and can be made into complex shaped hollow turbine blades working under $1100{ }^{\circ} \mathrm{C}$. At present, investigations of DZ125 alloy have been concentrated on the high-temperature strength such as tensile, creep and fatigue properties. There has been no research about its oxidation performance under high temperature. This paper deals with the hightemperature oxidation behavior of nickel-based superalloy DZ125 at $980{ }^{\circ} \mathrm{C}$. In order to study the interplay between the oxidation kinetics and oxide growth mechanics, a particular attention is paid to the effect of exposure time on the morphology and microstructure of the oxides as well as the thickness of the corresponding oxide layer evolution.

\section{Experimental Procedures}

The nickel-based superalloy DZ125 rods with [001] orientation were cast by means of crystal selection method in a directionally solidified furnace with high temperature gradient, and followed by a serious of heat treatment. The nominal composition of alloy is listed in Table 1.

The specimens were produced using wire-based electrical discharge machine along the [001] direction, and the surfaces subsequently were ground to 1200 grit finish using silicon carbide grinding paper to remove the recast layer resulting from the electrical discharge machining process. Following this, the specimens were degreased in acetone, ultrasonically cleaned in alcohol and dried in air. The size of specimens used was approximately $10 \mathrm{~mm} \times 10 \mathrm{~mm} \times 2 \mathrm{~mm}$.

Oxidation testing was conducted at the temperature of $980{ }^{\circ} \mathrm{C}$ in laboratory air for time up to $334 \mathrm{~h}$. Prior to testing, alumina crucible was heated for more than $100 \mathrm{~h}$ at $1000{ }^{\circ} \mathrm{C}$ until the weight is stable in the test environment. And then crucible and the specimens together were put into the furnace to be exposed to the air. Intermitted weighing at room temperature was carried out to study the oxidation kinetics. At appropriate time intervals, the specimens were taken out of the furnace and then weighed with an electronic balance with a resolution of $0.1 \mathrm{mg}$. Other three specimens were simultaneously tested at the same condition for $0.5,45$ and $95 \mathrm{~h}$ to further investigate the evolution process of the oxides.

After oxidation testing, the specimens were prepared for cross-sectional analysis by grinding on $\mathrm{SiC}$ papers down to 1200 grit followed by polishing with $1.5 \mu \mathrm{m}$ diamond paste. Then, the Zeiss Supra55 scanning electron microscopy (SEM) with $15 \mathrm{kV}$ voltages was used to measure the oxide layer thickness and to identify the morphology of the layer. X-ray energy dispersive spectroscopy (EDS) with $15 \mathrm{kV}$ voltages was used to analyze element distribution of the oxide layers of the specimens. X-ray diffraction (XRD) analysis of the surface oxides was performed on a Empyrean system using $\mathrm{Cu} K_{\alpha}$ radiation.

\section{Results and Discussion}

\subsection{Initial Microstructure of the DZ125 in As-Cast Condition}

The nickel-based superalloy DZ125 consists of a $\gamma$ matrix and approximately a $68 \%$ volume fraction of $\gamma^{\prime}$ precipitates as shown in Fig. 1. The chemical composition of the $\gamma$ was (in $\operatorname{mass} \%$ ) $3.28 \mathrm{Al}-13.98 \mathrm{Cr}-13.55 \mathrm{Co}-60.48 \mathrm{Ni}-8.71 \mathrm{~W}$, while the $\gamma^{\prime}$ precipitates contained (in mass \%) 7.43Al$3.48 \mathrm{Cr}-5.87 \mathrm{Co}-73.63 \mathrm{Ni}-8.24 \mathrm{~W}-1.35 \mathrm{Ti}$. The results of EDS showed that the contents of $\mathrm{Al}$ in $\gamma^{\prime}$ precipitate were higher than those in the $\gamma$ matrix. However, the contents of Ni were similar in the both phases.

\subsection{Oxidation Kinetics}

The mass gains per unit area $\left(\Delta m / A\right.$, in $\left.\mathrm{mg} / \mathrm{cm}^{2}\right)$ of the DZ125 as a function of oxidation time performed at $980{ }^{\circ} \mathrm{C}$ in air is shown in Fig. 2. No spallation was observed during the whole oxidation tests. It was apparent that the oxidefilm growth on the specimens proceeds by a rapidly increased at initial stage followed a gradually reduction stage of the oxide-film growth rate, especially after oxidation for $55 \mathrm{~h}$, the oxide growth rate drastically decreased.

Table 1 Chemical composition of DZ125 (wt\%)

\begin{tabular}{llllllllll}
\hline $\mathrm{C}$ & $\mathrm{Cr}$ & $\mathrm{Al}$ & $\mathrm{Co}$ & $\mathrm{Ti}$ & $\mathrm{W}$ & $\mathrm{Ta}$ & $\mathrm{Hf}$ & $\mathrm{M}$ & $\mathrm{Ni}$ \\
\hline 0.09 & 8.68 & 5.24 & 9.80 & 0.94 & 7.08 & 3.68 & 1.52 & 2.12 & 0.012 \\
\hline
\end{tabular}




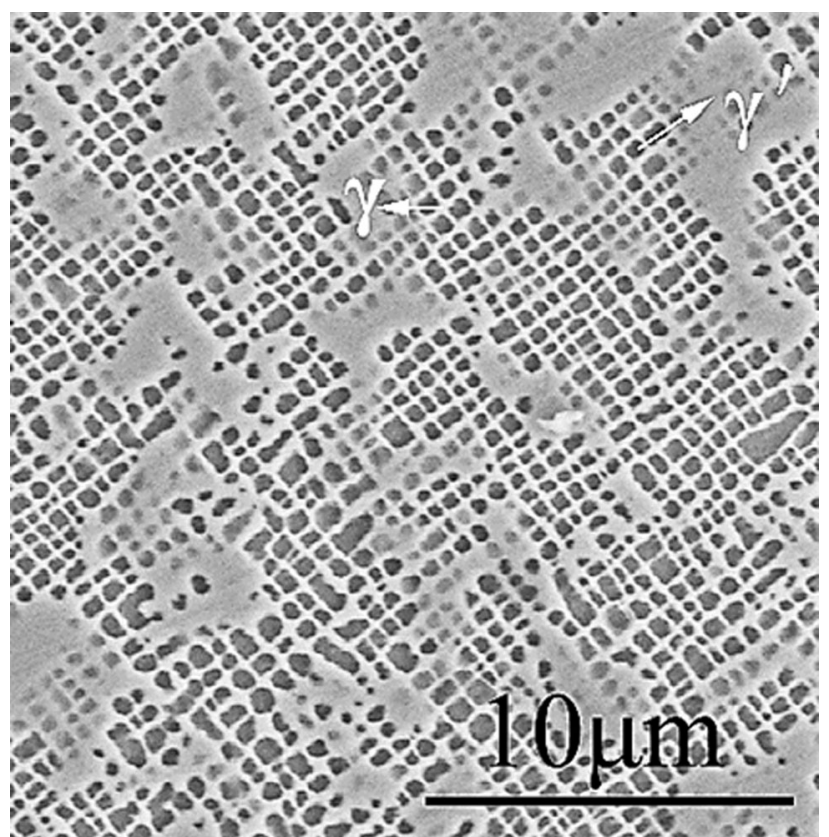

Fig. 1 Microstructure of DZ125 before the isothermal oxidation tests

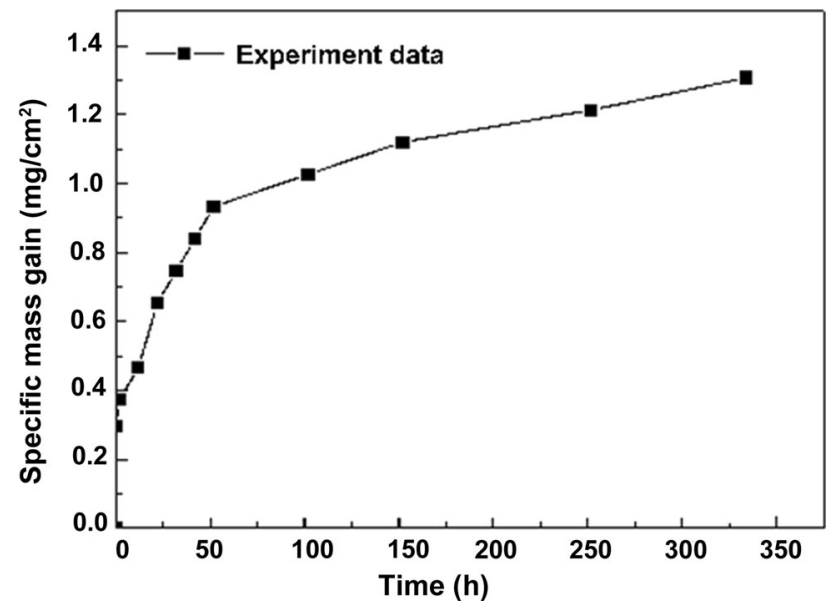

Fig. 2 Variation of specific mass gain with oxidation time of DZ125 at $980{ }^{\circ} \mathrm{C}$

The relationship between mass change and exposure time during oxidation usually follows an approximate power law $[12,14,17]$, which can be described as

$(\Delta m / A)^{n}=k t$,

where $\Delta m$ is the mass gain of the specimens, $A$ is the specimen surface area, $k$ is the oxidation rate constant, $t$ is the exposure time, and $n$ is value express oxidation reaction index which can be directly estimated by $\log -\log$ plot of the mass change versus exposure time. The values of $n$ were about $0.14,0.46$ and 0.18 during the periods of $0-2$, 2-55 and 55-334 h, respectively.
The results indicated that the oxidation behavior of DZ125 at $980{ }^{\circ} \mathrm{C}$ was not rigorously followed the parabolic law in the whole oxidation process, while it could be divided into three stages. The mass was gained rapidly at the initial of oxidation process $(<2 \mathrm{~h})$, and the oxidation rate developed to be zero virtually within less than about $55 \mathrm{~h}$, naming it entered to a steady stage. Oxidation process was a transient stage between 2 and $55 \mathrm{~h}$.

\subsection{Oxide Morphology and Composition}

Figure 3 shows the morphology of oxides products which were formed on the surface at various exposure time. After exposure for $0.5 \mathrm{~h}$, obvious oxidation was observed on the surface, as shown in Fig. 3a. EDS analysis showed that oxides formed on the surface can be roughly classified into two types as marked by 1,2 and 3 . The black region (point 3) was mainly consisted of $\mathrm{Al}$ and $\mathrm{O}$ element, which is in accordance with the references: in superalloy with high contents of $\mathrm{Cr}$, the continuous alumina film would form on the alloy surface when the content of $\mathrm{Al}$ is higher than $5 \%$ [17-19]. Whereas the $\mathrm{Ni}$ was rich in plate-like oxides which were randomly distributed on the surface (point 1), Ta and Hf were the major metallic constituents of the white isolated island particles (point 2). As shown in Fig. 3b, the oxides of the specimens after 45-h oxidation were analyzed. According to EDS spot analysis, the above three oxides could still be significantly observed on the surface corresponding to that for $0.5 \mathrm{~h}$. However, the plate-like oxides (point 1) were being connected each other and gradually bestrew the black areas (point 3 ) as the oxidation time increased. Nevertheless, the plate-like oxides (point 1) were already spread over the black regions (point 3 ) of the specimens after oxidation for $334 \mathrm{~h}$, as shown in Fig. 3c.

The back scattering electron (BSE) image of typical cross-sectional microstructure of nickel-based superalloy DZ125 after oxidation $334 \mathrm{~h}$ at $980{ }^{\circ} \mathrm{C}$ is shown in Fig. 4. The surface oxide scale is complex and can be divided into several layers. Besides, the detailed composition analysis is presented in Table 2. Beneath the oxide scale, it appeared a certain thickness of $\gamma^{\prime}$-free zone.

Based on the results of EDS, generally, the oxide formed on the surface at $980{ }^{\circ} \mathrm{C}$ for $334 \mathrm{~h}$ consisted of three layers. The outer layer was rich in $\mathrm{Ni}$ with a small amount of $\mathrm{Co}$ (point 1). And the intermediate layer can be classified into two layers (point 3 and points 2, 4, 5), predominantly composing of some complex spinels with a small amount of Ta-rich oxide (point 3 ). The inner layer contained many pores, and $\mathrm{Al}$ and $\mathrm{O}$ were segregated in this layer (point 6).

XRD result of the alloy surface after exposed $334 \mathrm{~h}$ is shown in Fig. 5, and the oxides formed on the surface were mainly composed of $\mathrm{Al}_{2} \mathrm{O}_{3}, \mathrm{NiCr}_{2} \mathrm{O}_{4}, \mathrm{CoCr}_{2} \mathrm{O}_{4}, \mathrm{HfO}_{2}$, $\mathrm{TaO}_{2}$ and $\mathrm{NiO}$. The results were in good agreement with 

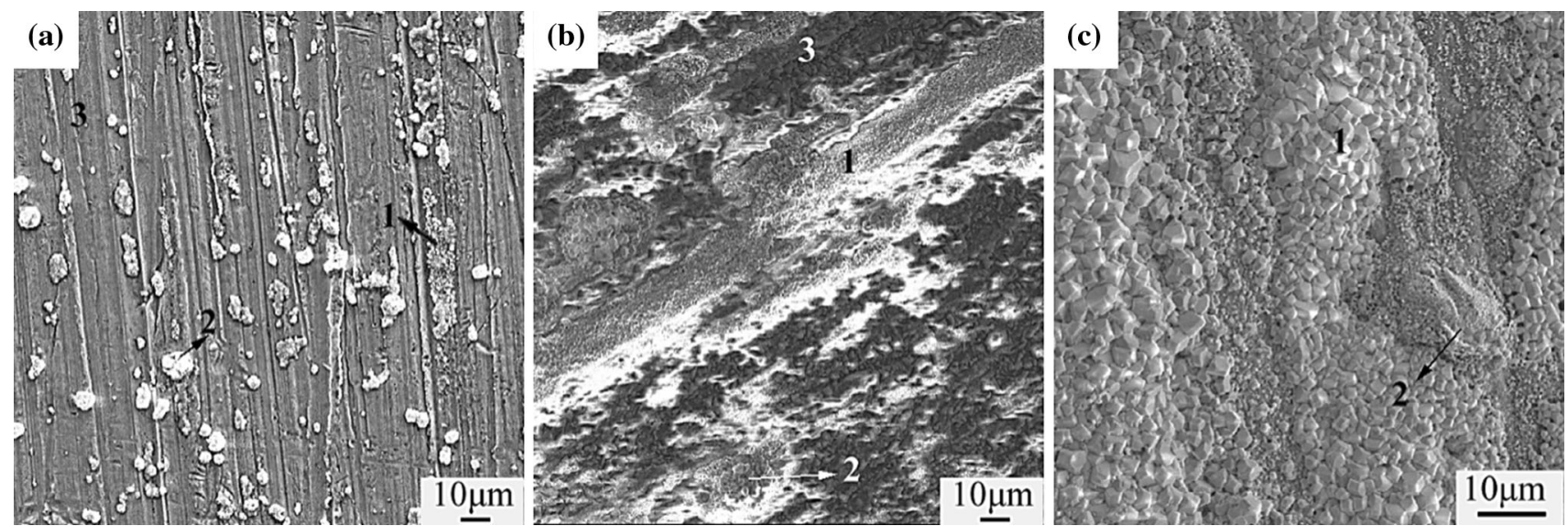

Fig. 3 Oxide morphology and chemical composition of the DZ125 at $980{ }^{\circ} \mathrm{C}$ at different exposure time: a after oxidation for $0.5 \mathrm{~h}$, whereas the region 1, 2 and 3 represented the different oxides which formed on the surface; $\mathbf{b}$ oxidation for $45 \mathrm{~h}$; $\mathbf{c}$ region 3 was covered by the region 1 after oxidation for $334 \mathrm{~h}$

Table 2 Chemical content of main elements in typical phase zone after oxidation at $980^{\circ} \mathrm{C}$ in Fig. 2

\begin{tabular}{lllllllll}
\hline Point & \multicolumn{7}{l}{ Element content $(\mathrm{wt} \%)$} \\
\cline { 2 - 9 } & $\mathrm{O}$ & $\mathrm{Al}$ & $\mathrm{Ni}$ & $\mathrm{Co}$ & $\mathrm{Cr}$ & $\mathrm{W}$ & $\mathrm{Ti}$ & $\mathrm{Ta}$ \\
\hline 1 & 29.6 & 0.7 & 62.6 & 7.1 & - & - & - & - \\
2 & 28.8 & 7 & 36.3 & 6.6 & 4.8 & - & 0.8 & - \\
3 & 23.6 & - & 15.4 & 3.6 & 6.2 & - & 4.4 & 46.9 \\
4 & 37.2 & 25.1 & 26.8 & 6.7 & 4.3 & - & - & - \\
5 & 37.7 & 33.4 & 19.5 & 5.6 & 3.9 & - & - & - \\
6 & 47.7 & 45.8 & 4.4 & - & 2.1 & - & - & - \\
\hline
\end{tabular}

the EDS analysis as shown in Table 2. Generally, combined with the results of XRD and EDS, the outer layer composed of $\mathrm{NiO}$ with a small amount of $\mathrm{CoO}$, and the inner layer was identified as $\alpha-\mathrm{Al}_{2} \mathrm{O}_{3}$. The multiphase complex intermediate layer contained $\mathrm{Ta}$ oxides and some spinel phases, such as $\mathrm{NiCr}_{2} \mathrm{O}_{4}$ and $\mathrm{CoCr}_{2} \mathrm{O}_{4}$.

Three distinguished layer were developed on the surface of the specimens, and the thicknesses of the alumina layer, total oxide layer as well as $\gamma^{\prime}$-free zone increased with increasing oxidation time, as shown in Fig. 6. After oxidation for $0.5 \mathrm{~h}$, a thickness of $1.2 \mu \mathrm{m} \gamma^{\prime}$-free zone accompanied by alumina layer was observed in the specimens; it was generally considered that the diffusion of $\mathrm{Al}$ by its own concentration gradients induced the oxidation reaction resulted in the formation of $\gamma^{\prime}$-free zone on the beneath of oxide film $[12,17,18,20]$. As the oxidation time increased, the total oxide layer showed faster growth rate than that of $\gamma^{\prime}$-free zone. However, the alumina layer increased slightly with increasing exposure time. This suggested that other cations must have an interaction effect with $\mathrm{Al}$ cations during the oxidation process.

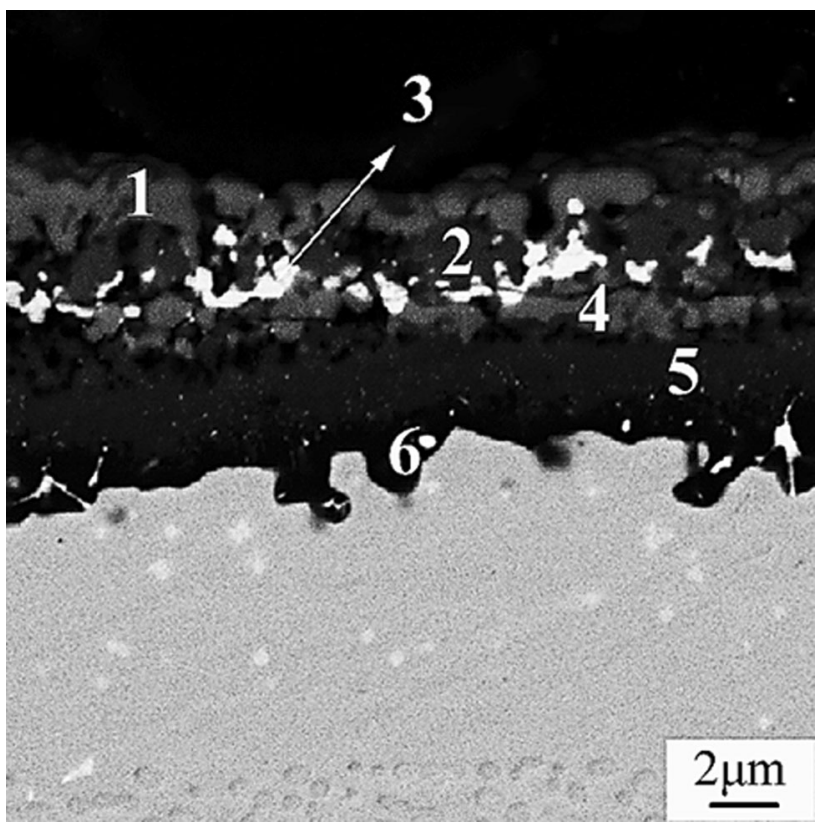

Fig. 4 Cross-sectional BSE image of nickel-based superalloy DZ125 after exposure for $334 \mathrm{~h}$

\subsection{Growth Mechanism of Oxide Scale}

The resultant relative charge difference in the oxide becomes the driving force for oxidation and controls the kinetics of the oxidation process. Accordingly, the metaldeficit oxides such as $\mathrm{Ni}, \mathrm{Cr}$ oxides grew outward from the surface of the alloy by the outward diffusion of metal cations to react with oxygen at the oxide/gas interface $[13,17,21]$. While the oxygen-deficit or n-type oxides such as $\mathrm{Al}$, Ta oxides grow inward from the surface by the diffusion of oxygen anions to react with metal cations at the oxide/metal interface $[14,17,22]$. 


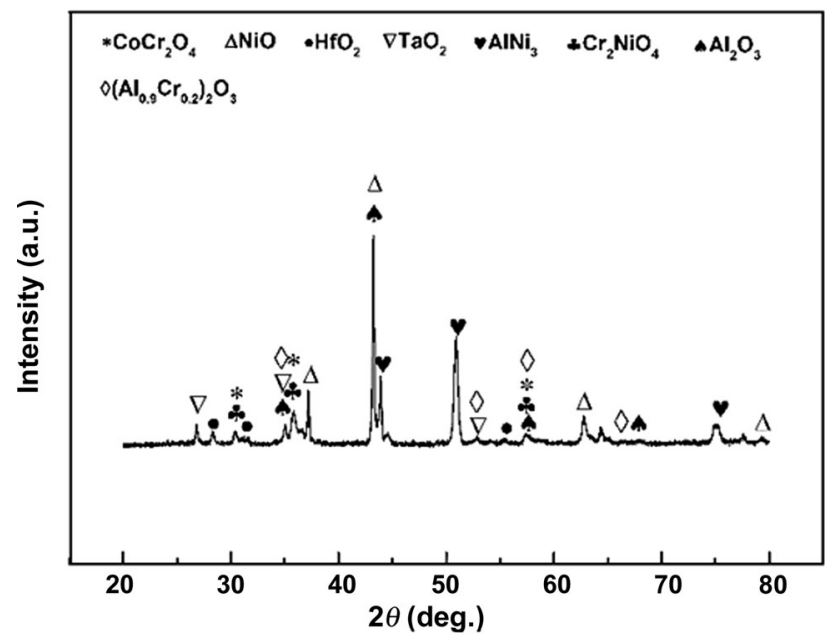

Fig. 5 XRD patterns of specimen after oxidation for $334 \mathrm{~h}$

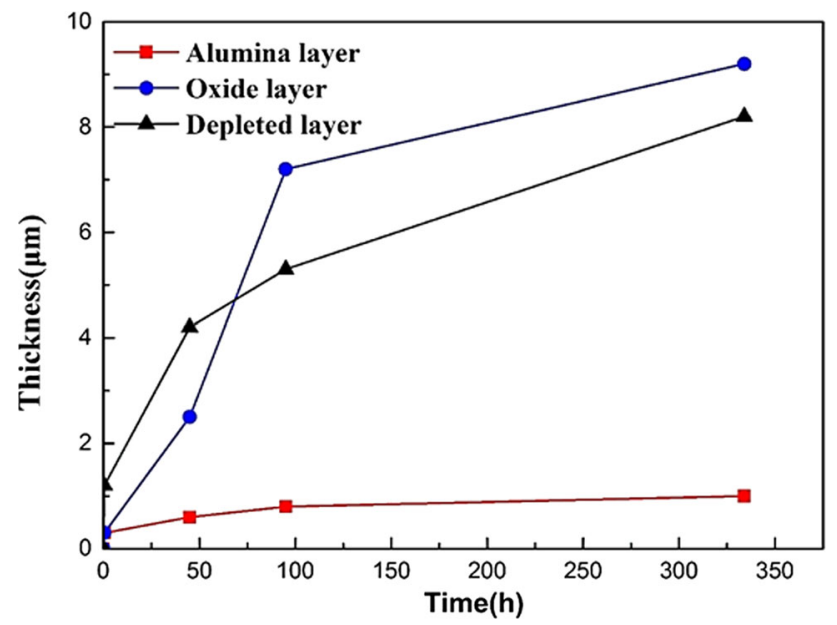

Fig. 6 Effect of exposure time on the thickness of different layer of DZ125

Based on the above results and discussions, it was verified that the oxidation behavior of DZ125 superalloy was controlled by the double diffusion of oxygen anions and $\mathrm{Ni}$, $\mathrm{Al}$, and $\mathrm{Cr}$ cations inwards and outwards, respectively. As presented in Fig. 7, the oxidation control mechanism of DZ125 at $980{ }^{\circ} \mathrm{C}$ is as follows. In the initial short-term oxidation stage (Fig. 7a), oxygen molecules were absorbed onto the surface of alloy and decomposed into oxygen atoms. Al has a high affinity with oxygen compared other cations of the alloy $[12,13,17,18]$ and resulting in a fast diffusion toward the metal/oxide interface to form alumina on the surface. Therefore, it concluded that the alumina growth controlled the oxidation kinetics in the initial stage, which leads to the mass rapidly to increase. As the oxidation time increased, the plate-like $\mathrm{NiO}$ was gradually connected each other and quickly built up on the surface, which caused the mass rapidly to increase in the transient stage (Fig. 7b). Meanwhile, the oxygen diffused inward (a)

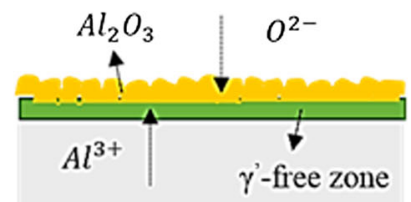

DZ125 substrate

(b)

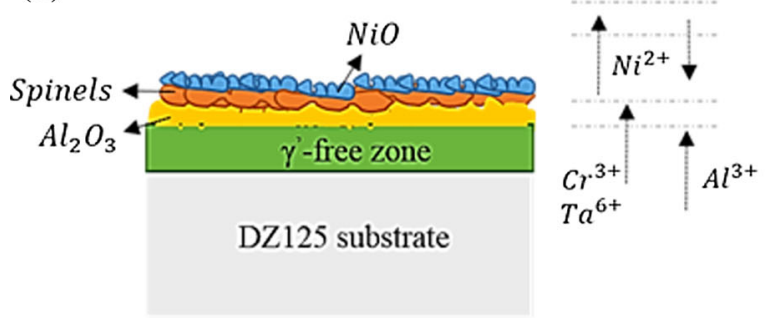

(c)
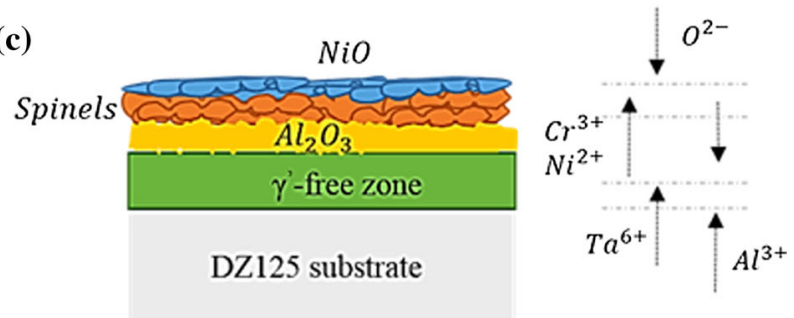

Fig. 7 Schematic illustration of the growth mechanism of oxide scale of the nickel-based superalloy DZ125 at $980{ }^{\circ} \mathrm{C}$ : a oxidation at the initial stage; b oxidation at the transient stage; c oxidation at the steady stage

through the external oxide layer to react with Ta cations to form the Ta-rich oxides. This was due to the fact that the external oxide layers were more permeable to oxygen than to metal cations, so that oxygen could easily traverse through these layers. $\mathrm{Ni}$ and $\mathrm{Cr}$ continued to migrate through these regions to form oxides compounds on the surface. Due to the formation of $\mathrm{NiO}, \mathrm{Cr}_{2} \mathrm{O}_{3}$ and $\mathrm{CoO}$, solid-state reactions occurred to form $\mathrm{Ni}-\mathrm{Cr}$ and $\mathrm{Cr}-\mathrm{Co}$ spinel phases $[13,14,17,20]$ as parts of the intermediate oxide layer in the ongoing oxidation stage. When the exposure time up to steady stage (Fig. 7c), due to a stable oxide film established on the surface, the oxygen partial pressure and diffusion rate of metal cations were decreased in the oxide film. Under such conditions, the mass change of the surface was abrupt to virtually zero.

\subsection{Interaction Between Oxidation and $\gamma^{\prime}$-Free Zone}

As stated above, Al was oxidized easily. The other cations of alloy diffused through the alumina layer to react with oxygen at scale/superalloy interface to form other oxides. Therefore, the growth rate of oxide scales was determined 
Table 3 Oxidation and depleted reaction index of DZ125 at different oxidation periods

\begin{tabular}{lll}
\hline Reaction index & Periods & \\
\cline { 2 - 3 } & Transient stage & Steady stage \\
\hline$n$ & 0.46 & 0.179 \\
$m$ & 0.462 & 0.171 \\
\hline
\end{tabular}

by the diffusion rate of cations through this layer. As $\gamma^{\prime}$ free zone and oxidation were both closely related to the diffusion rate of $\mathrm{Al}$, they should show similar kinetics in the whole oxidation process.

Generally, the average depth of depleted zone can be described as following function of time $t$ :

$d=D t^{m}$.

In the function, $D$ is the diffusion coefficient of $\mathrm{Al}$ in the superalloy, $m$ is the $\gamma^{\prime}$-free zone reaction index which can be directly estimated by $\log -\log$ plot of the thickness of $\gamma^{\prime}$ free zone versus exposure time.

Table 3 shows the results of $\gamma^{\prime}$-free zone reaction index $\mathrm{m}$ and oxidation reaction index $\mathrm{n}$ at different oxidation stages. The value of $\mathrm{m}$ was similar to that of oxidation reaction index $\mathrm{n}$ at the two stages. This indicated that the $\gamma^{\prime}$-free zone must have a significant effect on the diffusion coefficient or the diffusion rate of cations during the oxidation process. At the transient stage, the formation of alumina had not been exhausted of Al near the oxide-metal interface and the $\gamma^{\prime}$-free zone was thin so that the matrix can provide sufficient $\mathrm{Al}$ element for reaction. As the exposure time increased, the thickness of $\gamma^{\prime}$-free zone became sufficiently high enough for $\mathrm{Al}$ to diffuse a longer distance and reach the surface of the specimen, which led to the matrix became deficit of $\mathrm{Al}$ with the passage of time and reduced the diffusion rate of cations through the $\gamma^{\prime}$-free zone.

\section{Conclusions}

The isothermal oxidation behavior of Ni-base superalloy was studied at $980{ }^{\circ} \mathrm{C}$ at different exposure time. The conclusions can be summarized as follows:

1. The oxidation kinetics of DZ125 performed at $980{ }^{\circ} \mathrm{C}$ not strictly followed parabolic law during the whole oxidation, it can be divided into three stages.

2. The oxide scale structure of DZ125 was complicated and three layers can be observed. $\alpha-\mathrm{Al}_{2} \mathrm{O}_{3}$ was identified as the inner layer close to the substrate, and the outer layer consisted of $\mathrm{NiO}$ and a small amount of $\mathrm{CoO}$. The multiphase intermediate layer contained Ta oxides and some spinel phases such as $\mathrm{NiCr}_{2} \mathrm{O}_{4}$, and $\mathrm{CoCr}_{2} \mathrm{O}_{4}$.

3. Alumina formed initially on the surface only exposed for $0.5 \mathrm{~h}$, and then $\mathrm{Ta}, \mathrm{Ni}$ as well as $\mathrm{Cr}$ diffused through the alumina layer, which controlled the oxidation kinetics.

4. The first formation of alumina was responsible for the initial stage of weight loss, and the formation of $\mathrm{NiO}$ and intermediate layer may dramatically effect on the transient and steady stage, respectively.

Acknowledgements This work was supported by the National Natural Science Foundation of China (No. U1610256) and (No. 2015AA034402).

\section{References}

[1] R.Z. Wang, B. Chen, X.C. Zhang, S.T. Tu, J. Wang, C.C. Zhang, Int. J. Fatigue 97, 190-201 (2017)

[2] S.H. Cho, S.K. Lee, D.Y. Kim, J.H. Lee, J.M. Hur, J. Alloys Compd. 695, 2878-2885 (2017)

[3] A. Srivastava, S. Gopagoni, A. Needleman, V. Seetharaman, A. Staroselsky, R. Banerjee, Acta Mater. 60, 5697-5711 (2012)

[4] M.Z. Alam, D. Chatterjee, B. Venkataraman, V.K. Varma, D.K. Das, Mater. Sci. Eng. A 527, 6211-6218 (2010)

[5] A.L. Hutsona, T. Nicholasb, S.E. Olsona, N.E. Ashbaugha, Int. J. Fatigue 23, 445-453 (2001)

[6] M. Bensch, C.H. Konrad, E. Fleischmann, C.M.F. Rae, U. Glatzel, Mater. Sci. Eng. A 577, 179-188 (2013)

[7] Z.X. Wen, H.Q. Pei, Z.F. Yue, High Temp. Mater. Process. 35, 871-880 (2016)

[8] C.F. Miller, G.W. Simmons, R.P. Wie, Scr. Mater. 48, 103-108 (2003)

[9] A.A.N. Németh, D.J. Crudden, D.E.J. Armstrong, D.M. Collins, K. Li, A.J. Wilkinson, C.R.M. Grovenor, R.C. Reed, Acta Mater. 126, 361-371 (2017)

[10] S. Cruchely, H.Y. Li, H.F. Evans, P. Bowen, D.J. Child, M.C. Hardy, Int. J. Fatigue 81, 265-274 (2015)

[11] H.E. Evans, Int. Mater. Rev. 40, 1-40 (1995)

[12] J. Brenneman, J. Wei, Z. Sun, L. Liu, Y. Zhou, Corros. Sci. 100, 267-274 (2015)

[13] M.P. Taylor, H.E. Evans, S. Stekovic, M.C. Hardy, Mater. High Temp. 29, 145-150 (2012)

[14] A. Pfennig, B. Fedelich, Corros. Sci. 50, 2484-2492 (2008)

[15] S. Dryepondt, D. Monceau, F. Crabos, E. Andrieu, Acta Mater. 53, 4199-4209 (2005)

[16] X.Y. Yuan, Y.T. Yao, L.Q. Chen, Acta Metall. Sin. (Engl. Lett.) 27, 401-406 (2014)

[17] H.Q. Pei, Z.X. Wen, Z.F. Yue, J. Alloys Compd. 704, 218-226 (2017)

[18] S.J. Park, S.M. Seo, Y.S. Yoo, H.W. Jeong, H.J. Jang, Corros. Sci. 90, 305-312 (2015)

[19] N. Halem, M. Abrudeanu, G. Petot-Ervas, Mater. Sci. Eng. B 176, 1002-1009 (2011)

[20] A. Sato, Y.-L. Chiu, R.C. Reed, Acta Mater. 59, 225-240 (2011)

[21] J. Chapovaloff, F. Rouillard, K. Wolski, M. Pijolat, Corros. Sci. 69, 31-42 (2013)

[22] D.A. Jones, Principles and Prevention of Corrosion, 2nd edn. (Prentice Hall Press, Upper Saddle River, 1996) 